\title{
Preconcentration Method of Antimony Using Modified Thiol Cotton Fiber for Isotopic Analyses of Antimony in Natural Samples
}

\author{
Satoshi Asaoka, ${ }^{* \dagger}$ Yoshio TAKahASHI, ${ }^{*}$ Yuusuke ARAKI, ${ }^{*}$ and Masaharu TANIMIZU** \\ *Graduate School of Science, Hiroshima University, 1-3-1 Kagamiyama, Higashi-Hiroshima 739-8526, Japan \\ **Institute for Core Sample Research, KOCHI Japan Agency Marine-Earth Science and Technology, \\ 200 Monobe, Otsu, Nankoku 783-8502, Japan
}

\begin{abstract}
It is very important to investigate antimony geochemical behavior in order to identify its source, or reveal contamination processes, since antimony and its compounds are considered to be pollutants of high priority by the Environmental Protection Agency of the United States (USEPA). However, the concentration of antimony in most geological samples is very low, and its stable isotope mass difference is only 1.6\%. An antimony preconcentration method for isotope analysis using modified Thiol Cotton Fiber has been developed. Using this new method, the recovery of antimony was $99.5 \pm 3.6 \%$ $(n=3)$ and blank values were $<0.1 \mathrm{ng}$. The standard error of the $\varepsilon^{123} \mathrm{Sb}$ isotope ratios in the proposed method is only $0.4 \varepsilon$, much smaller than those of the previous method. The proposed method is therefore effective in the preconcentration and separation of antimony for antimony isotope analysis.
\end{abstract}

(Received June 30, 2010; Accepted December 8, 2010; Published January 10, 2011)

\section{Introduction}

Antimony is a naturally occurring element with more than $1.0 \times 10^{5}$ tons used annually in a variety of industrial applications, such as flame retardants, catalyst in plastics, pigment in paints, and additives in glassware, ceramics, ammunition, and battery. ${ }^{1-3}$ Since antimony compounds were considered to be pollutants of priority interest by the Environmental Protection Agency of the United States (USEPA), the concentration of antimony is regulated at less than $10 \mu \mathrm{g} \mathrm{L}^{-1}$ under the USEPA criteria. ${ }^{4}$ From a geochemical standpoint, typical concentrations of dissolved antimony in unpolluted water are less than $1 \mu \mathrm{g} \mathrm{L}^{-1}$. $^{5}$ The average antimony concentrations in fresh water and seawater are 1.1 and $0.18 \mu \mathrm{g} \mathrm{L}^{-1}$, respectively. ${ }^{5,6}$ Due to its lower abundance and the relative insolubility of most of its compounds, environmental concern for antimony has sometimes been overlooked.? Therefore, little information is available on its geochemical behavior or dynamics in the environment, which has been a scientific basis of recent studies on the environmental geochemistry of $\mathrm{Sb}^{8-10}$ Accordingly, it is very important to investigate antimony geochemical behavior in order to identify its source and to reveal its contamination mechanisms. For this purpose, antimony isotope variations in natural systems can be useful geochemical tracers by considering the different antimony isotopes among deep-sea sediments, hydrothermal sulfides, environmental samples, seawater, basalt and silicate rocks. ${ }^{11}$ Hence, it is possible that the antimony isotope can be used to identify the ultimate arsenic source in the hydrosphere. To apply such an isotopic method of source analysis of $\mathrm{Sb}$, it is

$\dagger$ To whom correspondence should be addressed.

E-mail: st-asaoka@hiroshima-u.ac.jp very desirable to develop a preconcentration method for natural samples that contains trace amounts of antimony. Before any antimony stable isotope analysis, there are some problems that need to be overcome, as follows: (1) concentrations of $\mathrm{Sb}$ in most geological samples and seawater are low at less than $100 \mathrm{ng} \mathrm{g}^{-1}$ and $300 \mathrm{ng} \mathrm{L}^{-1}$, respectively; ${ }^{11}$ (2) considering their small mass difference of only $1.6 \%$ between two $\mathrm{Sb}$ stable isotopes (121 and 123), the preconcentration and separation of antimony from other elements are essential to determine precisely the isotope ratio using a multiple collector, ICP-MS (MC-ICP-MS); (3) in particular, the separation of antimony from tellurium is important, since Te has isobaric Te-123 on Sb-123, which cannot be separated using a mass spectrometer; (4) because antimony, especially the trivalent species, is very volatile, ${ }^{12}$ antimony can be lost during evaporation in digestion and preconcentration processes; (5) high recovery is desirable to prevent isotopic fractionation through the preconcentration procedure.

Preconcentration and chemical separation methods for antimony commonly reported include chelating, coprecipitation and ion exchange. ${ }^{13-16}$ Thiol cotton fiber (TCF) is also used for the preconcentration and chemical separation of antimony. ${ }^{13,17}$ However, the results from the preconcentration and chemical separation for antimony using TCF varied among those studies. Therefore, we have developed an external correction method using tin isotopes. ${ }^{18}$ The measurement precision was $0.4 \varepsilon$, which is enough to distinguish antimony isotopes of sulfide ores, possible sources of antimony from usual terrestrial materials. ${ }^{11}$ This method is effective in determining antimony isotope ratios in terms of a low standard deviation. Hence, the antimony and tin in samples should be separated completely. However, antimony separation from a combined antimony and tin solution has not been tested, and blank values have not been mentioned in the previous papers. ${ }^{11,13,17}$ Thus, the purpose of 

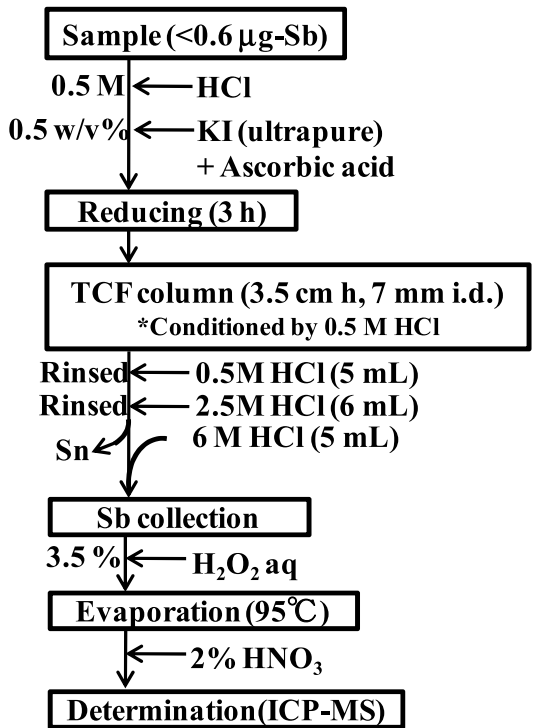

Fig. 1 Flow diagram of the proposed method for antimony preconcentration.

this study is to develop a preconcentration and separation method of antimony with high recovery for antimony isotope analyses using powdered Thiol Cotton Fiber (TCF).

\section{Experimental}

\section{Reagents}

A standard solution of $1000 \mathrm{mg} \mathrm{L}^{-1} \mathrm{Sb}(\mathrm{V})$ was prepared by adding an appropriate amount of $\mathrm{K}\left[\mathrm{Sb}(\mathrm{OH})_{6}\right]$ (Wako Pure Chemical Industries, Ltd.) into $100 \mathrm{~mL}$ of ultrapure water (18.2 M $\Omega$ ), and the solution was ultrasonicated for $c a .2 \mathrm{~h}$ in order to dissolve the standard reagent completely. A commercially available standard (Wako Pure Chemical Industries, Ltd.) was used for a Sn standard solution. A standard solution of $1000 \mathrm{mg} \mathrm{L}^{-1} \mathrm{Te}(\mathrm{VI})$ was prepared by adding an appropriate amount of $\mathrm{Na}_{2} \mathrm{H}_{4} \mathrm{TeO}_{6}$ (Wako Pure Chemical Industries, Ltd.) into $100 \mathrm{~mL}$ of ultra pure water. Before use, the solutions were successively diluted in each experiment. All chemicals used in this study were ultrapure analytical reagents (Tama Chemicals Co., Ltd.) unless otherwise stated. A mixed reducing agent $(10 \mathrm{w} / \mathrm{v} \%$ potassium iodide and $10 \mathrm{w} / \mathrm{v} \%$ ascorbic acid) for $\mathrm{Sb}(\mathrm{V})$ was prepared by dissolving an appropriate amount of $>99.998 \%$ potassium iodide (SigmaAldrich Co.) and ascorbic acid (Kanto Chemicals Co., Inc.) into ultrapure water every time before use.

\section{Preparation of TCF}

Mercaptoacetic acid (100 mL) (Wako Pure Chemical Industries, Ltd.), $60 \mathrm{~mL}$ of acetic anhydride (Wako Pure Chemical Industries, Ltd.), $40 \mathrm{~mL}$ of acetic acid $(36 \%)$ and $0.3 \mathrm{ml}$ of sulfuric acid $\left(18 \mathrm{~mol} \mathrm{~L}^{-1}\right)$ (Tama Chemicals Co., Ltd.) were mixed successively in a wide-mouth bottle, and the mixture was cooled to room temperature. Thereafter, $30 \mathrm{~g}$ of medical absorbent cotton (H153; PIP-FUJIMOTO Co., Ltd.) was thoroughly impregnated in the solution. After the top of the bottle was closed tightly, the bottle was kept at $40^{\circ} \mathrm{C}$ in an oven for $4 \mathrm{~d}$. Thereafter, the TCF was washed fully with ultrapure water and then dried at $30^{\circ} \mathrm{C} .{ }^{13}$ The TCF was stored at $c a .20^{\circ} \mathrm{C}$ in a sealed container protected from light. Before use, the TCF
Table 1 Chemical composition of reducer for antimony

\begin{tabular}{cccccc}
\hline Condition & $\begin{array}{c}\mathrm{HCl} / \\
\mathrm{M}\end{array}$ & $\begin{array}{c}\text { Ascorbic } \\
\text { acid, w/v\% }\end{array}$ & $\begin{array}{c}\mathrm{KI}, \\
\text { w/v\% }\end{array}$ & $\begin{array}{c}\mathrm{NH}_{2} \mathrm{OH} \cdot \mathrm{HCl}, \\
\text { w/v\% }\end{array}$ & $\begin{array}{c}\text { Rec., } \\
\%\end{array}$ \\
\hline $\mathrm{A}$ & 0.5 & 0.5 & - & - & 8.8 \\
$\mathrm{~B}$ & 0.5 & 0.5 & 0.5 & - & $>95$ \\
$\mathrm{C}$ & 0.5 & 0.5 & - & 0.5 & 13 \\
\hline
\end{tabular}

was pulverized using a food processor with ceramic blades to minimize any variation of recovery during preconcentration using TCF. Thereafter, the TCF was rinsed by ultrapure water in a centrifugation tube and centrifuged (3000 rpm) several times for $5 \mathrm{~min}$ to remove suspended fractions.

\section{Preconcentration and chemical separation procedure}

The optimized procedure is shown in Fig. 1. After TCF ( $c a$. $1.3 \mathrm{~mL})$ was packed in a mini column $(3.5 \mathrm{~cm} \mathrm{~h}, 7 \mathrm{~mm}$ i.d.; disposable $2 \mathrm{~mL}$ polystyrene columns, Thermo Fisher Scientific K.K.), the TCF was conditioned by introducing sequentially $25 \mathrm{~mL}$ of ultrapure water and $25 \mathrm{~mL}$ of $0.5 \mathrm{M} \mathrm{HCl}$. Antimony in sample solutions adjusted to $0.5 \mathrm{M} \mathrm{HCl}$ was reduced to $\mathrm{Sb}$ (III) by adding a $10 \mathrm{w} / \mathrm{v} \% \mathrm{KI}$-ascorbic acid mixed solution to make $0.5 \mathrm{w} / \mathrm{v} \%$ of the final concentration for $3 \mathrm{~h}$. Subsequently, the sample was passed through a column packed with TCF at ca. $100 \mathrm{~mL} \mathrm{~h}^{-1}$. After the column was rinsed with $5 \mathrm{~mL}$ of $0.5 \mathrm{~mol} \mathrm{~L}^{-1} \mathrm{HCl}$ and $6 \mathrm{~mL}$ of $2.5 \mathrm{~mol} \mathrm{~L}^{-1} \mathrm{HCl}$ successively, the $\mathrm{Sb}$ fraction was collected by passing $5 \mathrm{~mL}$ of $6 \mathrm{~mol} \mathrm{~L}^{-1} \mathrm{HCl}$ through the column. The $\mathrm{H}_{2} \mathrm{O}_{2}$ (with final concentration of $3.5 \mathrm{w} / \mathrm{v} \%$ ) was added to an aliquot of the $\mathrm{Sb}$ fraction and evaporated to dryness at $95^{\circ} \mathrm{C}$. The concentration of antimony was determined using an ICP-MS (7500; Agilent Technologies), and the $\mathrm{Sb}$ isotope was analyzed by a multicollector ICP-MS (Neptune; Thermo Fisher Scientific K.K.) coupled with an external correction method using $\mathrm{Sn}$ isotopes. ${ }^{18}$

\section{Results and Discussion}

\section{Reducing conditions}

Antimony(V) is the predominant species present in aerobic conditions while $\mathrm{Sb}$ (III) species increase to $93 \%$ only in the sample under the anoxic condition. ${ }^{5}$ Since TCF can retain $\mathrm{Sb}(\mathrm{III})$ selectively, but not so for $\mathrm{Sb}(\mathrm{V}),{ }^{13,17}$ reducing reagents for converting $\mathrm{Sb}(\mathrm{V})$ to $\mathrm{Sb}(\mathrm{III})$, such as (A) ascorbic acid solution, (B) KI-ascorbic acid mixed solution and (C) hydroxylamine hydrochloride-ascorbic acid mixed solution were tested. These reagents, adjusted to a $0.5 \mathrm{w} / \mathrm{v} \%$ final concentration, were added to $100 \mathrm{~mL}$ of $0.45 \mu \mathrm{m}$ filtered reservoir water (in Hiroshima University, Japan) samples $\left(0.5 \mathrm{~mol} \mathrm{~L}^{-1} \mathrm{HCl}\right.$ solution) spiked with $0.1 \mu \mathrm{g}$ of $\mathrm{Sb}(\mathrm{V})$ and $0.1 \mu \mathrm{g}$ of $\mathrm{Sn}(\mathrm{II})$. The recoveries of antimony were $8.8,13$ and $>95 \%$ for the ascorbic acid solution, the hydroxylamine hydrochloride-ascorbic acid mixed solution and the KI-ascorbic acid mixed solution, respectively (Table 1$)$. When only the KI-ascorbic acid mixed solution $(0.5 \mathrm{w} / \mathrm{v} \%$ final concentration) was used for antimony reduction, high recovery was achieved. However, KI reagent contains $\mathrm{Sb}$ and $\mathrm{Sn}$ as impurities. A blank test was conducted followed by this proposed method using a KI reagent produced by three companies in order to lower the blank from the reagents. The blank was lowest when using KI reagent (>99.998\%) purchased from Sigma-Aldrich Co., which was subsequently used for following experiments.

The time required for reducing $\mathrm{Sb}$ was also investigated in the 


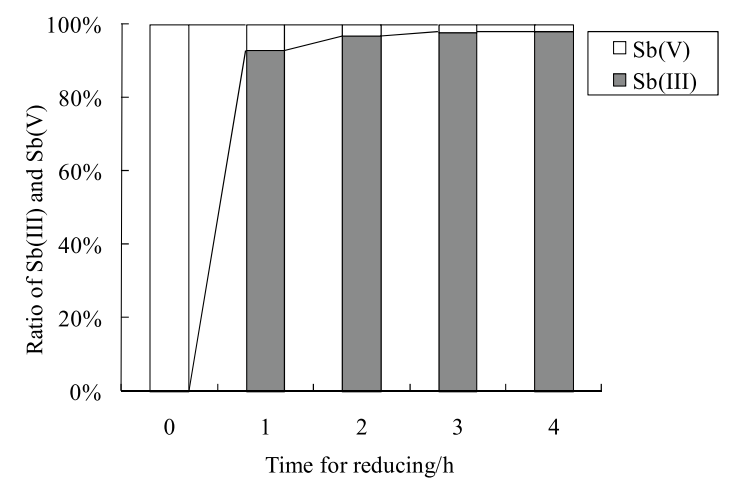

Fig. 2 Change in the ratio of $\mathrm{Sb}(\mathrm{III})$ and (V) over time for reducing.

range of 0 to $4 \mathrm{~h}$ by $\mathrm{KI}$ and an ascorbic acid mixed solution $(0.5 \mathrm{w} / \mathrm{v} \%$ final concentration $)$ as a reducing solution. The change of the $\mathrm{Sb}(\mathrm{III})$ and $\mathrm{Sb}(\mathrm{V})$ ratio over time was measured using LC-ICP-MS; ${ }^{19} 98 \%$ of $\mathrm{Sb}(\mathrm{V})$ was reduced in $3 \mathrm{~h}$ and the ratio was constant (Fig. 2). Thus, the time for the reduction was set to $3 \mathrm{~h}$.

\section{Separation conditions}

The concentration of $\mathrm{HCl}$ for the separation of $\mathrm{Sn}$ from the $\mathrm{Sb}$ fraction was investigated in the range of 2.5 to $6 \mathrm{~mol} \mathrm{~L}^{-1} \mathrm{HCl}$. Tin was eluted completely by a $2.5 \mathrm{~mol} \mathrm{~L}^{-1}$ or more concentrated $\mathrm{HCl}$ solution. On the other hand, $\mathrm{Sb}$ did not elute by the $\mathrm{HCl}$ solution at a concentration less than $3 \mathrm{~mol} \mathrm{~L}^{-1}$, and $\mathrm{Sb}$ was collected perfectly by introducing $6 \mathrm{~mol} \mathrm{~L}^{-1}$ of $\mathrm{HCl}$. Thus, Sb can be separated from Sn completely by introducing $2.5 \mathrm{~mol} \mathrm{~L}^{-1}$ $\mathrm{HCl}$.

The volume of the $\mathrm{HCl}$ solution introduced was also optimized to collect Sb. Antimony $(0.1 \mu \mathrm{g})$ was introduced to a column packed with $1.3 \mathrm{~mL}$ of TCF, followed by the procedure shown in Fig. 1. When more than $4 \mathrm{~mL}$ of $6 \mathrm{~mol} \mathrm{~L}^{-1} \mathrm{HCl}$ was introduced into the column, $\mathrm{Sb}$ was collected completely (Fig. 2). The optimum volume of $\mathrm{HCl}$ solution was fixed at $5 \mathrm{~mL}$ to ensure complete recovery of $\mathrm{Sb}$. On the other hand, the recovery of $\mathrm{Sb}$ upon introducing $10 \mu \mathrm{g}$ of $\mathrm{Sb}$ sample loading was around $82 \%$. Thus, $1.3 \mathrm{~mL}$ of TCF was used in the mini column, and the Sb retaining capacity of TCF was $6 \mu \mathrm{g} \mathrm{mL}^{-1}$ TCF. Consequently, $5 \mathrm{~mL}$ of $0.5 \mathrm{~mol} \mathrm{~L}^{-1} \mathrm{HCl}$ and $6 \mathrm{~mL}$ of $2.5 \mathrm{~mol} \mathrm{~L}^{-1} \mathrm{HCl}$ were introduced successively to separate the reducing reagent and $\mathrm{Sn}$ before $\mathrm{Sb}$ collection; thereafter, the $\mathrm{Sb}$ fraction was collected by introducing $5 \mathrm{~mL}$ of $6 \mathrm{~mol} \mathrm{~L}^{-1} \mathrm{HCl}$.

Tellurium contamination in the $\mathrm{Sb}$ fraction was investigated because tellurium has a 123 stable isotope, which is isobaric to ${ }^{123} \mathrm{Sb}$. After about $0.1 \mu \mathrm{g}$ of Te was loaded, the present method was performed as shown above. As a result, the concentration of $\mathrm{Te}$ in the $\mathrm{Sb}$ fraction was below the detection limit. Therefore, $\mathrm{Te}$ was also separated completely from $\mathrm{Sb}$, and the effect of $\mathrm{Te}$ on $\mathrm{Sb}$ analysis was insignificant.

A blank test was also conducted following the same procedure. The blank value was less than $0.1 \mathrm{ng}$ for $\mathrm{Sb}$ and less than $0.7 \mathrm{ng}$ for $\mathrm{Sn}$. These values are also negligible for the analysis of $\mathrm{Sb}$ in natural samples.

\section{Evaporation conditions}

After the elution of $\mathrm{Sb}$ using a $6 \mathrm{~mol} \mathrm{~L}^{-1} \mathrm{HCl}$ solution, the solution was converted into $2 \% \mathrm{HNO}_{3}$ prior to isotope analysis, since a $\mathrm{HCl}$ solution forms molecular ions of $\mathrm{MCl}$ (M: metal ion) in MC-ICP-MS analyses. Hence, the evaporation condition
Table 2 Recovery percentages of antimony under the various oxidizer condition

\begin{tabular}{|c|c|c|c|c|c|}
\hline Condition & $\begin{array}{c}\mathrm{H}_{2} \mathrm{O}_{2} \\
\%\end{array}$ & $\begin{array}{c}\mathrm{HNO}_{3}, \\
\%\end{array}$ & $\begin{array}{c}\mathrm{HClO}_{4}, \\
\%\end{array}$ & $\begin{array}{c}\text { Evaporation } \\
\text { temp } /{ }^{\circ} \mathrm{C}\end{array}$ & $\begin{array}{c}\text { Recovery, } \\
\%\end{array}$ \\
\hline A & 3.5 & - & - & 95 & 97 \\
\hline B & 17.5 & - & - & 95 & 99 \\
\hline C & 3.5 & 6.8 & - & 95 & 89 \\
\hline D & 3.5 & - & 23 & 120 & 50 \\
\hline
\end{tabular}

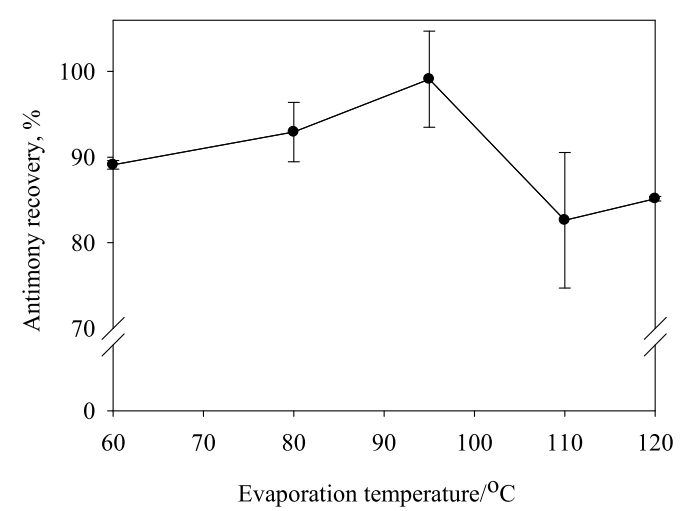

Fig. 3 Recovery of antimony under various evaporation temperatures.

without Sb loss due to volatilization was validated. Antimony, especially the trivalent species, is very volatile, ${ }^{12}$ and can be lost during digestion and evaporation processes. An oxidizer to prevent $\mathrm{Sb}$ from volatilization was tested using a $6 \mathrm{~mol} \mathrm{~L}^{-1} \mathrm{HCl}$ solution spiked with $0.1 \mu \mathrm{g}$ of $\mathrm{Sb}$, which was the same concentration of $\mathrm{Sb}$ in the $\mathrm{Sb}$ fraction after passing through TCF column. The oxidizer compositions tested in this study and antimony recovery are given in Table 2 . The evaporation temperature under condition $\mathrm{D}$ was $120^{\circ} \mathrm{C}$, since $\mathrm{HClO}_{4}$ has a high boiling temperature of $203^{\circ} \mathrm{C}$. The others were set at $95^{\circ} \mathrm{C}$. When $\mathrm{H}_{2} \mathrm{O}_{2}$ was used as an oxidizer (= conditions $\mathrm{A}$ and $\mathrm{B}$ ), a high recovery of $\mathrm{Sb}$ was achieved. $\mathrm{HClO}_{4}$ was not suitable as an oxidizer in this case, because its boiling point was very high, thus causing the loss of $\mathrm{Sb}$. The concentration of $\mathrm{H}_{2} \mathrm{O}_{2}$ was set at $3.5 \mathrm{w} / \mathrm{v} \%$ as a final concentration because severe forming was observed at $17.5 \mathrm{w} / \mathrm{v} \%$ and therefore, not prone to evaporation.

The absolute amount of $\mathrm{Sb}$ added into the column was tested within the range of $0.01-50 \mu \mathrm{g}$. Antimony was recovered well up to $15 \mu \mathrm{g}$, but its recovery decreased at more than $15 \mu \mathrm{g}$. Thus, the maximum amount of $\mathrm{Sb}$ under the evaporation process should be set at $15 \mu \mathrm{g}$. However, when the duration required for evaporation exceeded $6 \mathrm{~h}$, its recovery decreased slightly. To prevent Sb loss, a large Teflon vessel should be used for the evaporation to have a larger contact area on the hot plate, by which we can shorten the duration required for evaporation.

The evaporation temperature was studied using a $6 \mathrm{~mol} \mathrm{~L}^{-1}$ $\mathrm{HCl}$ solution spiked with $0.1 \mu \mathrm{g}$ of $\mathrm{Sb}$ within the range of $60-120^{\circ} \mathrm{C}$ (Fig. 3). The recovery was optimum at $95^{\circ} \mathrm{C}$, and decreased at lower or higher temperatures due to a longer evaporation time and volatilization during evaporation, respectively. Hence, the $95^{\circ} \mathrm{C}$ was selected for the evaporation process. 
Table 3 Recovery of antimony

\begin{tabular}{|c|c|c|c|}
\hline & 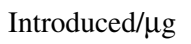 & Detected/ $\mu \mathrm{g}$ & Recovery, \% \\
\hline RUN1 & 0.109 & 0.107 & 97.6 \\
\hline RUN2 & 0.110 & 0.107 & 97.1 \\
\hline RUN3 & 0.110 & 0.114 & 104.0 \\
\hline A.V. & & & 99.5 \\
\hline SD & & & 3.6 \\
\hline $\mathrm{RSD}, \%$ & & & 3.7 \\
\hline
\end{tabular}

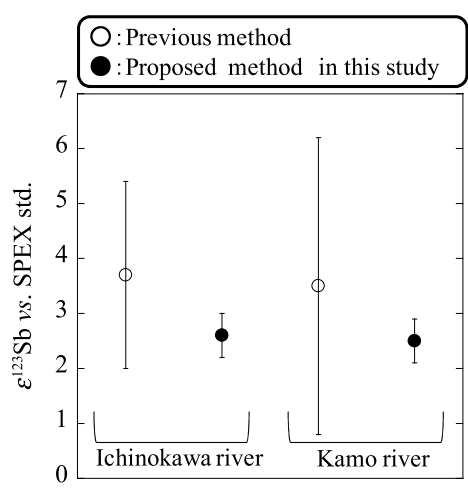

Fig. $4 \varepsilon$ values of $\mathrm{Sb}$ obtained using previous method and the proposed method developed in this study. Error bars are standard error.

\section{Analytical performances}

The recovery test was conducted with the results summarized in Table 3, showing that the recoveries of $\mathrm{Sb}$ from ultrapure water spiked with $0.1 \mu \mathrm{g} \mathrm{Sb}$ was more than $97 \%$. The natural water samples collected from Ichinokawa river ( $\mathrm{Sb}$ concentration, $113 \mu \mathrm{g} \mathrm{L}^{-1}$; loading, $3 \mathrm{~mL}$ ), which is affected by significant antimony loads from the Ichinokawa abandoned mines, known to have one of the highest stibnite outputs in the world, located on Shikoku Island, southwestern Japan. Water samples from downstream of Kamo river ( $\mathrm{Sb}$ concentration, $1.5 \mu \mathrm{g} \mathrm{L}^{-1}$; loading, $100 \mathrm{~mL}$ ), which is also affected by antimony load from Ichinokawa river joining, were also tested. In both cases their recoveries were more than $95 \%$. Antimony in water samples was collected effectively using the proposed method in the present study.

Antimony isotope analysis was conducted following previous reports, ${ }^{11,13,17}$ and the proposed method developed in this study (Fig. 4). The antimony isotope analysis was conducted at Kochi Institute for Core Sample Research using MC-ICP-MS (Thermo Finnigan Neptune). Since, the previous method cannot separate Sn from Sb completely, about 1 - 5 ng of Sn was contaminated in the $\mathrm{Sb}$ fraction. Therefore, an external correction method using Sn cannot be applied, and therefore the Bracketing method was performed instead of the external correction method in order to correct the mass distinction effect. ${ }^{20}$ Consequently, the standard error of $\varepsilon^{123} \mathrm{Sb}$ isotope ratios show high values $(1.7-2.7 \varepsilon)$. On the other hand, since the proposed method developed in this study can separate Sn from Sb completely, and the external correction method can be applied to $\mathrm{Sb}$ isotope analysis, the standard error of the $\varepsilon^{123} \mathrm{Sb}$ isotope ratios in the proposed method is only $0.4 \varepsilon$, much smaller than those of the previous method. The proposed method is therefore effective in the preconcentration and separation of antimony for antimony isotope analysis.

\section{Conclusions}

The proposed method is effective in the preconcentration and separation of antimony for isotope analysis in terms of its high recovery, and showing a small standard error coupled with the Sn external correction method.

\section{Acknowledgements}

This research was supported by the Global Environment Research Fund granted by the Ministry of the Environment Japan (RF-084a) and Research Project for Ensuring Food Safety from Farm to Table AC-1110. This manuscript has been subjected to rigorous internal review and critically edited by a native English speaker Dr. Lawrence M. Liao of the Graduate School of Biosphere Science, Hiroshima University.

\section{References}

1. M. Filella and P. M. May, Geochim. Cosmochim. Acta, 2003, 67, 4013.

2. K. A. Herbst, G. Rose, K. Hanusch, H. Schumann, and H. U. Wolf, "Antimony and Antimony Compounds", ed. K Hunger, P. Mischke, and W. Rieper, 1985, Wiley-VCH, Weinheim, 55.

3. X. Guo, Z. Wu, and M. He, Water Res., 2009, 43, 4327.

4. USEPA, "Antimony: an Environmental and Health Effects Assessment", 1984, US Environmental Protection Agency, Office of Drinking Water, Washington, D.C.

5. M. Filella, N. Belzile, and Y. W. Chen, Earth Sci. Rev., 2002, 57, 125.

6. D. P. Kharkar, K. K. Turekian, and K. K. Bertine, Geochim. Cosmochim. Acta, 1968, 32, 285.

7. M. Filella, N. Belzile, and Y. W. Chen, Earth Sci. Rev., 2002, 59, 265.

8. A. C. Scheinost, A. Rossberg, D. Vantelon, I. Xifra, R. Kretzschmar, A.-K. Leuz, H. Funke, and C. A. Johnson, Geochim. Cosmochim. Acta, 2006, 70, 3299.

9. S. Mitsunobu, T. Harada, and Y. Takahashi, Environ. Sci. Technol., 2006, 40, 7270.

10. S. Mitsunobu, Y. Takahashi, and Y. Terada, Environ. Sci. Technol., 2010, 44, 1281.

11. O. Rouxel, J. Ludden, and Y. Fouquet, Chem. Geol., 2003, 200, 25.

12. J. Klein, S. Dorge, G. Trouvé, D. Venditti, and S. Durécu, J. Hazard. Mater., 2009, 166, 585.

13. M. Yu, G. Liu, and Q. Jin, Talanta, 1983, 30, 265.

14. A. Erdem and A. E. Eroğlu, Talanta, 2005, 68, 86

15. Y. C. Sun and J. Y. Yang, Anal. Chim. Acta, 1999, 395, 293.

16. K. W. W. Sims and E. S. Gladney, Anal. Chim. Acta, 1991, 251, 297.

17. M. Yu, D. Sun, W. Tian, G. Wang, W. Shen, and N. Xu, Anal. Chim. Acta, 2002, 456, 147.

18. M. Tanimizu, Y. Araki, S. Asaoka, and Y. Takahashi, Geochem. J., in press.

19. S. Mitsunobu, T. Takahashi, and Y. Sakai, Chemosphere, 2008, 70, 942

20. A. Cocherie and M. Robert, Chem. Geol., 2007, 243, 90. 